Journal of Social and Development Sciences

Vol. 5, No. 2, pp. 79-88, Jun 2014 (ISSN 2221-1152)

\title{
Regional Inequalities of Land associated to Health Facilities in Rural India
}

\author{
${ }^{*}$ Moumita Poddar ${ }^{1}$, Sandip Mitra ${ }^{2}$ \\ ${ }^{1}$ Raja Peary Mohan College, Uttarpara, Hooghly, WB, India \\ ${ }^{2}$ Indian Statistical Institute, Kolkata, WB, India \\ *moumitas.econ@gmail.com
}

\begin{abstract}
Rural population is often considered as a homogeneous population. The wide diversity among rural population is often ignored when health related issues are considered. The study emphasizes that heterogeneous composition of rural population leads to improper implementation of rural health facilities, which in turn leads to poor health conditions. It is argued that wide divergences in rural sector should be understood to roll out any such policy for the rural sector in particular. This paper attempts to show how heterogeneity in rural population affects the health status. The burden of disease and its effects are disproportionately seen in the poor, with a clear gradient in illness and morbidity. The most affected are the poor and vulnerable section of the population. The privileged section in rural society is termed as 'Rural elite'. Attempts have been made to define rural elites in terms of ownership of better facilities and endowments (like land). It is argued that the elites enjoy health facilities and have better health conditions. On the contrary, health status of rural poor is abysmal. The objective of the study is to explore the disparities between these two groups and examine how these disparities affect health conditions. The study reveals that the incidence of selective diseases is much lower in the case of rural elites. Despite progress in improving access to health care, inequalities by socioeconomic status continue to persist.
\end{abstract}

Keywords: Rural elite, Rural Poor, Incidence of disease, Land ownership, Regional inequality

\section{Introduction}

Health as a basic socio economic indicator is particularly important to the people in the developing world like India. Evidence shows that rates of social development is lower than that has been hoped for and even more steadily rising population growth has precipitated a reaction against public health programs. This leads to the challenges to ensure health opportunity for all and distributive justice. Planning Commission 2011 reported that there is a clearly articulated government intention to increase the public financing of health to $2.5 \%$ of India's GDP during $12^{\text {th }}$ plan. The recognition of investment in health as both a developmental imperative and a pathway for winning popular political support has been evident in many recent initiatives ranging from the National Rural Health Mission (NRHM), the Rashtriya Swasthya Bima Yojana (RSBY) etc. Current study tries to focus on rural sector only. It is argued that wide divergences in rural sector should be understood to roll out any such policy for the rural sector in particular. Rural population is often considered as a homogeneous population. The wide diversity among rural population is often ignored when health related issues are considered. The study emphasizes that heterogeneous composition of rural population leads to improper implementation of rural health facilities, which in turn leads to poor health conditions. This paper attempts to show how heterogeneity in rural population affects the health status. The burden of disease and its effects are disproportionately seen in the poor, with a clear gradient in illness and morbidity. The most affected are the poor and vulnerable section of the population. The privileged section in rural society (often termed as 'rural elites' by sociologists) is different in many ways than other sections. Attempts have been made to define rural elites in terms of ownership of better facilities and endowments (like land). It is argued that the elites enjoy health facilities and have better health conditions. On the contrary, health status of rural poor is abysmal. The objective of the study is to explore the disparities between these two groups and examine how these disparities affect health conditions. This study reassures the importance to understand the heterogeneity in the rural population and indicates the need for separate policy intervention as a thrust to promote better health conditions for the rural poor.

The objective of the present study has been pointed out- 
- This paper tries to understand rural health with respect to access to own irrigated land, access to sanitation facility, access to protected source of drinking water, occupation, type of house. It attempts to show how heterogeneity in rural population affects the health status. Selected diseases have been identified as the indicators of health status.

- Land is considered as an important indicator of wellbeing in rural areas. The study highlights the gap in standard of living between rural elite and rural poor and the differential impacts across various states and India as a whole.

- The paper wants to examine whether incidence of specific diseases are lower among rural elites. The paper wants to understand if land ownership lead to better health conditions for rural elites.

- In this connection, the paper attempts to examine if the interstate disparities in land holding leads to disparity in health status

- As a policy implication, the study points out the impediments for universal health policy.

\section{Literature Review}

Latest Census estimates (2011) showed that most of India's population (68.84\%) lives in rural India. According to Rao (1983), there was a persistent feeling that rural development ought to receive higher priority and larger resources than it has received until now in the Indian development plans. Kurian (2000), Pradhan et al. (2000), Dholakia (2003) had already identified regional disparities across rural and urban population in India. However, the nature of rural population is not recognized widely. Hartley (2004) addressed the fact that many studies have investigated the effect of place of residence or community on health, but very few studies have focused on distribution of rural populations. Rural health disparities has been documented in Health United States, 2001, Urban and Rural Chartbook. Thus regional differences reinforce the need for a difference-based rural health policy. Johnson (2001) approached that recent trends in rural health research and policy suggest that effective policy interventions must be based on differences among rural regions. Rao (1983) attempted to view rural development as an economic process of interaction between two unequal entities - on the one hand, a large number of relatively small and dispersed villages and, on the other, the larger economy which is the dominant entity setting the direction and pace of the process. Patil et al. (2002) found that the rural populations, who are the prime victims of the policies, work in the most hazardous atmosphere and live in abysmal living conditions. Unsafe and unhygienic birth practices, unclean water, poor nutrition, subhuman habitats, and degraded and unsanitary environments are challenges to the public health system. The majority of the rural populations are smallholders, artisans and laborers, with limited resources that they spend chiefly on food and necessities such as clothing and shelter. They have no money left to spend on health. The majority of rural deaths, which are preventable, are due to infections and communicable, parasitic and respiratory diseases. Infectious diseases dominate the morbidity pattern in rural areas. Thus, India's health system faces the ongoing challenge of responding to the needs of the most disadvantaged members of Indian society. Despite progress in improving access to health care, inequalities by socioeconomic status continue to persist.

Wamani et al. (2004) had argued that the association of four socio-economic indicators namely: mothers' education, fathers' education, household asset index, and land ownership with growth stunting, which is used as a proxy for health and nutrition inequalities among infants and young children. Rosenzweig and Evenson (1977) reported a positive effect of land size on fertility, suggesting that "reducing the inequality of holdings would increase family size in India". Schutjer et al. (1983) had also recognized the fact that land is usually given special socio-economic status in subsistence communities and the distribution of land is a primary determinant of the rural income distribution in many developing nations. Thus, all these studies have pointed out that better socio economic status in terms of having land, education, and spending pattern has significant effect on rural health conditions. This paper will consider land as an important indicator for better standard of living in rural areas. Thus, the inference of this study is better standard of living leads to better health outcomes. This paper will now talk on health outcomes before going into the details. According to Deodhar NS (2001), there are three groups of infections are widespread in rural areas, as follows.

- Diseases that are carried in the gastrointestinal tract, such as diarrhea, amoebiasis, typhoid fever, infectious hepatitis, worm infestations and poliomyelitis. About 100 million suffer from diarrhea and cholera every year. 
- Airborne diseases such as measles, tuberculosis (TB), whooping cough and pneumonia. Today there are 12 million TB cases (an average of 70\%). Over 1.2 million cases are added every year and 37000 cases of measles are reported every year.

- Infections, which are more difficult to deal with, include malaria, filariasis and kala-azar.

Based on these three types of diseases groups, this paper has considered three types of diseasesTuberculosis, Asthma and diarrhea. According to WHO, Diarrheal disease is the second leading cause of death in children under five years old and is responsible for killing around 760000 children every year. Globally, there are nearly 1.7 billion cases of diarrheal disease every year. A significant proportion of diarrheal disease can be prevented through safe drinking-water and adequate sanitation and hygiene. Asthma is a chronic respiratory disease. WHO estimates that 235 million people currently suffer from asthma. Asthma is a public health problem not just for high-income countries; it occurs in all countries regardless of the level of development. Most asthma-related deaths occur in low- and lower-middle income countries. According to WHO, indoor allergies are another important cause for asthma. Thus, for the prevention of acute diarrheal diseases and acute respiratory diseases requires improved sanitation facility, access to safe drinking water, access to employment which can generate sufficient income and lastly, better housing facility. Heterogeneity existing in rural sector affects the prevalence of different diseases. The burden of diseases and the effects are disproportionately seen in the poor, with a clear gradient in illness and morbidity. In this paper, we will argue that expanding health facilities in rural India doesn't help much to curb rural health issues as there is a need to check whether rural poor have actual access to such facilities. The source of ambiguity lies in the uncertainty that rural elites are ending up with better health conditions than rural poor. Thus, differences in rural sector need to be recognized along with the urban-rural differentials.

\section{Methodology}

The present study uses Third National Family Health Survey (NFHS-3) data conducted in India during 20052006 (IIPS, 2007) under the stewardship of the Ministry of Health and Family Welfare, Government of India designating International Institute of Population Sciences (IIPS) as the nodal agency for the survey and was funded by Government of India along with foreign agencies. The survey was conducted among representative samples of ever-married women in the age group of 15 - 49 years. This study uses the data of rural India only. The indicators identified from the NFHS-3 survey data as per the requirement of the study objective are as follows.

- Ownership of irrigated land (L) : 1: If has irrigated land; 2: If has no irrigated land

- Sanitation Facility (S) : 1: Has any type of sanitation facility; 2: No sanitation facility

- Source of drinking water (D) : 1: Protected source; 2: Unprotected source

- Respondent's occupation (0) : 1: Employed; 2: Unemployed

- Type of house (H): 1: If has good type of floor, roof and wall (Pucca); 2: If has bad type of floor, roof and wall (Kaccha). In Pucca houses, floor material includes brick, stone, Ceramic tiles, cement etc, roof material includes wood, cement fiber, asbestos sheets, tiles etc and wall material includes cement, cement blocks, stones and brick etc. In Kacchahouses, floor material includes mud, sand, dung, palm, bamboo etc, roof material includes palm leaf, mud, plastic or polythene sheets, bamboo etc and wall material includes mud, bamboo, raw and unused woods etc.

- Incidence of disease (DIS): 1: If has Asthma or TB or Diarrhea; 0: If doesn't have above mentioned diseases.

- Status of rural household (STS): 1: Rural elite; 2: Rural poor

- Considering land as an important indicator, rural population has been categorized in two groups in terms of own irrigated land.. In this paper, we will define rural elites, those who have own irrigated land. On the contrary, those who haven't irrigated land will be called rural poor. In this paper, the predictor variable 'status of rural household (STS) has these two categories, rural elite and rural poor.

Multiple logistic analysis has been used to find out the effect of land along with other variables on the incidence of disease.

Algebraically, this can be written as 
$\log _{e}\{\mathrm{P} /(1-\mathrm{P})\}=\mathrm{a}+\mathrm{b}(\mathrm{L}, \mathrm{S}, \mathrm{D}, \mathrm{O}, \mathrm{H})$, where, $\mathrm{P}=$ Probability $\{$ ISEASE $=1\}, \mathrm{b}>0$

$\log _{e}\{P /(1-P)\}=\alpha+\beta_{1} L+\beta_{2} S+\beta_{3} D+\beta_{4} O+\beta_{5} H$

where, $\mathrm{P}=$ Probability $\{\mathrm{DIS}=1\}$ and $\quad \beta_{i}>0$

Next, this paper will focus on the importance of land on other variables separately. A regression analysis has been used to find out the effect of land on owning other above mentioned variables.

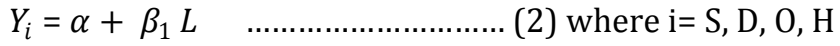

Further, we also check effect of status of rural household on the incidence of disease.

Algebraically, this can be written as,

$\log _{e}\{P /(1-P)\}=\alpha+\beta_{1}(S T S)$

where, $\mathrm{P}=$ Probability $\{\mathrm{DIS}=1\}$ and

$$
\beta_{1}>0
$$

\section{Results \& Discussion}

Distribution of the predictor variables (ownership of land, sanitation facility, type of house, respondent's occupation, source of drinking water) of the model has been explained using from the NFHS3 data. Table 1 shows that almost 66\% rural household doesn't have irrigated land. Almost 70\% rural households do not have sanitation facility. 29\% rural households use protected source of drinking water. Almost 56\% rural populations are unemployed. Almost 84\% households have kaccha house. Almost $34 \%$ rural populations belong to the rural elite category according to the methodology used in this study.

Table 1: Percentage distribution of the predictor variables

\begin{tabular}{lll}
\hline Predictor Variables & Category & Share or Percentage \\
\hline Land use (L) & Irrigated land & 33.53 \\
& No irrigated land & 66.47 \\
Sanitation Facility (S) & Has any type of sanitation facility & 30.73 \\
& No sanitation facility & 69.27 \\
Source of drinking water (D) & Protected source & 71.35 \\
& Unprotected source & 28.65 \\
Respondent's occupation (O) & Employed & 43.99 \\
& Unemployed & 56.01 \\
Type of house (H) & Pucca House & 16.42 \\
& Kaccha House & 83.58 \\
Status of rural household (STS) & Rural elite & 3353 \\
& Rural poor & 66.47 \\
\hline
\end{tabular}

Table 2-6 depicts percentage distribution of the predictor variables (ownership of land, sanitation facility, type of house, respondent's occupation, source of drinking water) state-wise. North eastern states and UTs have been omitted.

Table 2: Percentage Distribution of Land use state wise

\begin{tabular}{lcl}
\hline \multicolumn{2}{l}{ Land use state wise } & \\
\hline State & Irrigated land & No irrigated land \\
\hline Jammu & $\&$ & \\
Kashmir & 44.77 & 55.23 \\
Himachal & & \\
Pradesh & 19.68 & 80.32 \\
Punjab & 33.18 & 66.82 \\
Uttaranchal & 34.28 & 65.72 \\
Haryana & 34.48 & 65.52 \\
Rajasthan & 38.98 & 61.02
\end{tabular}




\begin{tabular}{lll} 
Uttar Pradesh & \multicolumn{1}{c}{38.26} & 38.74 \\
\cline { 2 - 3 } Bihar & 44.65 & 55.35 \\
West Bengal & 29.01 & 70.99 \\
Jharkhand & 23.15 & 76.85 \\
Orissa & 18.96 & 81.04 \\
Chhattisgarh & 32.58 & 67.42 \\
Madhya & & \\
Pradesh & 31 & 69 \\
Gujarat & 38.72 & 61.28 \\
Maharashtra & 27.09 & 72.91 \\
Andhra & & \\
Pradesh & 27.18 & 72.82 \\
Karnataka & 27.89 & 72.11 \\
Kerala & 10.3 & 89.7 \\
Tamil Nadu & 20.36 & 79.64 \\
Total & 33.53 & 66.47 \\
\hline
\end{tabular}

Table 2 shows that, Uttar Pradesh has the highest irrigated land holding (61.26\%) and Kerala has the lowest land holding (10.3\%).Bihar has the second highest landholding (44.65\%).

Table 3: Distribution of Sanitation Facility State wise

\begin{tabular}{lll}
\hline $\begin{array}{l}\text { Sanitation Facility State wise } \\
\text { State }\end{array}$ & Any type of facility & No facility \\
\hline Jammu \& Kashmir & 43.72 & 56.28 \\
Himachal Pradesh & 32.75 & 67.25 \\
Punjab & 49.47 & 50.53 \\
Uttaranchal & 35.71 & 64.29 \\
Haryana & 29.33 & 70.67 \\
Rajasthan & 7.06 & 92.94 \\
Uttar Pradesh & 11.22 & 88.78 \\
Bihar & 13.2 & 86.8 \\
west Bengal & 35.11 & 64.89 \\
Jharkhand & 3.62 & 96.38 \\
Orissa & 9.37 & 90.63 \\
Chhattisgarh & 4.71 & 95.29 \\
Madhya Pradesh & 8.25 & 91.75 \\
Gujarat & 21.16 & 78.84 \\
Maharashtra & 21.56 & 78.44 \\
Andhra Pradesh & 20.59 & 79.41 \\
Karnataka & 17.36 & 82.64 \\
Kerala & 80.84 & 19.16 \\
Tamil Nadu & 14.73 & 85.27 \\
Total & 30.73 & 69.27 \\
\hline
\end{tabular}


Jharkhand has the lowest, only 3.62\% rural population has any types of sanitation facility and Kerala has the highest, $80.84 \%$ rural population has sanitation facility (Table 3). Punjab has the second highest percentage (49.47\%) of sanitation facility in India.

Table 4: Distribution of Source of Drinking water State wise

\begin{tabular}{lll}
\hline $\begin{array}{ll}\text { Source of drinking water State wise } \\
\text { State }\end{array}$ & Protected Source & Unprotected source \\
\hline Jammu \& Kashmir & 63.57 & 36.43 \\
Himachal Pradesh & 81.54 & 18.46 \\
Punjab & 9191 & 8.09 \\
Uttaranchal & 80.07 & 19.93 \\
Haryana & 84.88 & 15.12 \\
Rajasthan & 63.65 & 36.35 \\
Uttar Pradesh & 83.17 & 16.83 \\
Bihar & 85.31 & 14.69 \\
West Bengal & 85.29 & 14.71 \\
Jharkhand & 44.95 & 55.05 \\
Orissa & 69.89 & 30.11 \\
Chhattisgarh & 67.51 & 32.49 \\
Madhya Pradesh & 62.06 & 37.94 \\
Gujarat & 75.73 & 24.27 \\
Maharashtra & 77.41 & 22.59 \\
Andhra Pradesh & 77.88 & 22.12 \\
Karnataka & 70.22 & 29.78 \\
Kerala & 57.33 & 42.67 \\
Tamil Nadu & 87.78 & 12.22 \\
Total & 71.35 & 28.65 \\
\hline
\end{tabular}

Table 4 shows that in Punjab almost 91\% rural population has protected source of drinking water, which is the highest among Indian states. Jharkhand has the lowest percentage (44.95\%) of protected drinking water facility.

Table 5: Distribution of respondent's occupation state wise

\begin{tabular}{lll}
\hline $\begin{array}{l}\text { Respondent's Occupation State wise } \\
\text { State }\end{array}$ & Employed & Unemployed \\
\hline Jammu \& Kashmir & 38.01 & 61.99 \\
Himachalpradesh & 28.98 & 71.02 \\
Punjab & 17.47 & 82.53 \\
Uttaranchal & 45.78 & 54.22 \\
Haryana & 26.51 & 73.49 \\
Rajasthan & 62.4 & 37.6 \\
Uttarpradesh & 33.83 & 66.17 \\
Bihar & 37.36 & 62.64 \\
West Bengal & 30.95 & 69.05 \\
\hline
\end{tabular}




\begin{tabular}{lcc}
\hline Jharkhand & 69.11 & 30.89 \\
Orissa & 35.99 & 64.01 \\
Chhattisgarh & 8022 & 19.78 \\
Madhyapradesh & 61.89 & 38.11 \\
Gujarat & 55.37 & 44.63 \\
Maharashtra & 55.11 & 44.89 \\
Andhrapradesh & 51.88 & 48.12 \\
Karnataka & 44.63 & 55.37 \\
Kerala & 15.82 & 84.18 \\
Tamilnadu & 41.2 & 58.8 \\
Total & 43.99 & 56.01 \\
\hline
\end{tabular}

Table 5 shows that Chhattisgarh is the state with highest employed rural population $(80.22 \%)$ and Kerala has the lowest employed rural population $(15.82 \%)$.

Table 6: Distribution of Type of House State wise

\begin{tabular}{lll}
\hline $\begin{array}{l}\text { Type of House State Wise } \\
\text { State }\end{array}$ & Pucca House & Kaccha House \\
\hline Jammu and Kashmir & 28.62 & 71.38 \\
Himachal Pradesh & 32.61 & 67.39 \\
Punjab & 31.18 & 68.82 \\
Uttaranchal & 31.22 & 68.78 \\
Haryana & 20.67 & 79.33 \\
Rajasthan & 29.68 & 70.32 \\
Uttar Pradesh & 9.34 & 90.66 \\
Bihar & 11.08 & 88.92 \\
west Bengal & 10.13 & 89.87 \\
Jharkhand & 8.67 & 91.33 \\
Orissa & 17.1 & 82.9 \\
Chhattisgarh & 6.73 & 93.27 \\
Madhyapradesh & 8.19 & 91.81 \\
Gujarat & 26.48 & 73.52 \\
Maharashtra & 26.62 & 73.38 \\
Andhrapradesh & 27.41 & 72.59 \\
Karnataka & 15.13 & 84.87 \\
Kerala & 37.01 & 62.99 \\
Tamilnadu & 32.1 & 67.9 \\
Total & 16.42 & 83.58 \\
\hline
\end{tabular}

Table 6 dictates that Chhattisgarh has the highest percentage (93.27\%) of kaccha house. It is clear from these percentage distributions that there exist wide interstate disparities in land holding, sanitation facility, type of houses, source of drinking water and respondent's occupation. The disparity is best explained through the regression results. 
Table 7 narrates how differential health status can be explained based on disparity in standards of living. As mentioned earlier (equation 1), Logistic regression analysis has been undertaken to understand the effect of all the relevant variables on the incidence of diseases. The overall model is statistically significant. Looking at the table it is found that the odd ratios, here, are greater than 1(thereby indicating that the probability of occurrence of the disease increases as we move from category 1 to 2 for each of these variables). $\mathrm{Z}$ statistics are also significant at $1 \%$ level with a p value 0.000 indicating that these variables are highly significantly in occurrence of incidence of disease. Thus, incidence of disease is significantly high those who doesn't have irrigated land, access to sanitation facility, access to protected source of drinking water, are not employed and do not own pucca houses.

Table 7: Results of Logistic regression (Equation1)

\begin{tabular}{llll}
\cline { 1 - 2 } No. of observations & $\mathbf{3 2 0 5 2}$ & & \\
\cline { 1 - 2 } LR Chi2 (5) & 2986.70 & & \\
Prob> chi2 & & & \\
\cline { 1 - 2 } Pseduo R & & & \\
\cline { 1 - 2 } Predictor Variables & Odd ratios & Z statistics & P>|Z| \\
\cline { 1 - 2 } L_2 & $1.71^{* * *}$ & 14.66 & 0.000 \\
S_2 & $1.92^{* * *}$ & 17.21 & 0.000 \\
D_2 & $3.78^{* * *}$ & 42.24 & 0.000 \\
O_2 & $1.45^{* * *}$ & 11.81 & 0.000 \\
H_2 & $1.37^{* * *}$ & 6.91 & 0.000 \\
\hline
\end{tabular}

Attempts have been made to explore the scenario for various states of India. Table 8 represents the results of logistic regression for major states of India. Land, source of drinking water, respondent's occupation has significant impact on the health status for majority of the states. This signifies these predictor variables have a significant impact on the health status. Among all the states, in Karnataka, all the predictor variables depict the significant impact. Drinking water has a significant impact on all the states. Land has a significant impact in almost every state except three states (Kerala, Himachal Pradesh, Tamil Nadu and Uttaranchal). In six states (Punjab, West Bengal, Orissa, Gujarat, Maharashtra, Andhra Pradesh and Kerala) four out of five predictor variables are found to be significant. In two other states (Himachal Pradesh and Tamil Nadu) only one significant predictor variable is observed. Thus the existence of regional disparity in the rural sector is revealed to large extent.

Table 8: Results of Logistic regression state- wise

\begin{tabular}{llllll}
\hline State & Land_2 & $\begin{array}{l}\text { Drinking } \\
\text { water_2 }\end{array}$ & Sanitation_2 & House_2 & Ocu_2 \\
\hline $\begin{array}{l}\text { Himachal } \\
\text { Pradesh }\end{array}$ & 1.52 & $3.18^{* * *}$ & 1.35 & 1.43 & 1.27 \\
Punjab & $2.16^{* * *}$ & $132.14^{* * *}$ & $0.48^{* *}$ & $1.98^{* * *}$ & 0.78 \\
Uttaranchal & 1.27 & $2.89^{* * *}$ & $1.77^{* * *}$ & 0.95 & $1.35^{*}$ \\
Haryana & $1.68^{* * *}$ & $22.08^{* * *}$ & 1.06 & 0.94 & 0.71 \\
Rajasthan & $2.77^{* * *}$ & $3.62^{* * *}$ & 0.94 & $1.47^{* * *}$ & 0.83 \\
Uttar Pradesh & $2.4^{* * *}$ & $9.68^{* * *}$ & 1.29 & 1.1 & 1.02 \\
Bihar & $1.53^{* * *}$ & $26.06^{* * *}$ & 0.97 & 0.97 & 1.1 \\
West Bengal & $1.89^{* * *}$ & $6.88^{* * *}$ & $1.61^{* * *}$ & 1.22 & $1.89^{* * *}$ \\
Jharkhand & 1.32 & $1.94^{* * *}$ & 1.59 & $2.12^{* *}$ & $2.08^{* * *}$ \\
Orissa & $1.53^{* *}$ & $3.79^{* * *}$ & 0.97 & $2.33^{* * *}$ & $1.42^{* * *}$ \\
Chhattisgarh & $1.49^{* *}$ & $4.88^{* * *}$ & 1.77 & 0.76 & $1.71^{* * *}$ \\
Madhya & $2.04^{* * *}$ & $2.94^{* * *}$ & 1.25 & 1.00 & 1.09 \\
Pradesh & & & & & \\
& & & & & $1.42^{* *}$ \\
Gujarat & $1.46^{* *}$ & $2.77^{* * *}$ & $1.88^{* * *}$ & & \\
\hline
\end{tabular}




\begin{tabular}{llllll}
\hline Maharashtra & $1.83^{* * *}$ & $5.27^{* * *}$ & 0.84 & $1.66^{* *}$ & $2.06^{* * *}$ \\
$\begin{array}{l}\text { Andhra } \\
\text { Pradesh }\end{array}$ & $2.01^{* *}$ & $18.53^{* * *}$ & 0.69 & $6.25^{* * *}$ & $1.83^{* * *}$ \\
Karnataka & $2.83^{* * *}$ & & & & \\
Kerala & 0.69 & $7.23^{* * *}$ & $1.62^{* *}$ & $2.4^{* * *}$ & $2.18^{* * *}$ \\
Tamil Nadu & 1.17 & $2.53^{* * *}$ & $19.9^{* * *}$ & $1.83^{* *}$ & $2.64^{* * *}$ \\
\hline
\end{tabular}

Land ownership is found to affect significantly several other factors (like respondent's occupation, type of house, source of drinking water and sanitation facility). Table 9 shows the results of regression analysis. This reassures the impact of land ownership on the rural households.

Table 9: Regression analysis of other variables on Land

\begin{tabular}{llll}
\hline Predicted Variables & Coefficient & T value & P>t \\
\hline D_2 & 0.14 & 26.61 & 0.00 \\
S_2 & 0.11 & 2.03 & 0.43 \\
O_2 & 0.04 & 7.43 & 0.00 \\
H_2 & 0.05 & 13.40 & 0.00 \\
\hline
\end{tabular}

*Predictor variable: Land (L_2)

To identify separate effect of land on the overall health status, the study considers two groups of rural population based on type of land ownership (status of irrigation being the basis of such classification).The privileged section, owning proportionally higher irrigable land is named as 'rural elite'. On the contrary, those who haven't irrigated land will be called rural poor. Table 10 shows the effect of land holding on the health status of rural elite. Thus, logistic regression indicates the fact that rural elite enjoy better health conditions that rural poor. Thus, ownership of irrigated land marks a significant difference in the health status within the rural population. Though rural elite and rural poor reside in the same area, rural elite enjoys a better health status than rural poor. Thus, the dichotomy in the rural sector should be clearly understood for important interventions in rural sector.

Table 10: Result of Logistic Regression (Equation 2)

\begin{tabular}{llll}
\hline Predictor Variables & Odd Ratio & Z Statistics & $\mathbf{P}>|\mathbf{Z}|$ \\
\hline STS_2 & $2.15^{* * *}$ & 21.76 & 0.00 \\
\hline
\end{tabular}

\section{Conclusion}

India continues to be among the countries of the world having high incidence of diseases. This paper points out the importance to understand the heterogeneity in the rural population and appropriate targeting of vulnerable groups will be important to promote better health conditions to the rural poor by proper targeting. There is thus a need for a paradigm shift in health policies.

Recommendations: The study discusses important issues relating to rural health which are often ignored in the literature of development studies. As the Government of India had been increasingly mooting the idea of universal health policy, there is a further need to understand the nuances (including disparities in standard of living among the rural population) before the actual implementation. The disparity in the Landownership in a rural economy appears to be one of the major determinants of any policy intervention for the sake of inclusive growth

\section{References}

Deodhar, N. S. (2001). Health Situation in India (1st ed), New Delhi: Voluntary Health Association of India. Dholakia, R. H. (2003). Regional Disparity in Economic and Human Development in India. Economic and Political Weekly, 38(39), 4166-4172.

Hartley, D. (2004). Rural Health Disparities, Population Health and Rural Culture. Am J Public Health, 94, 1675-1678. 
Health, United States. (2001). Urban and Rural Chartbook. Department of Health and Human Services.

International Institute for Population Sciences (IIPS) and Macro International. Third National Family Health Survey (NFHS-3), 2005-06: India, Volumes I and II, (Mumbai: IIPS). 2007.

Johnson, S. (2001). Focusing on differences: a new approach for rural policy? Center for the study of rural America.

Kurian, N. J. (2000). Widening Regional Disparities in India: Some Indicators. Economic and Political Weekly, 35(7), 538-550.

Office of the Registrar General of India Ministry of Home Affairs. Census of India. New Delhi, India; 2011.

Patil, A. V., Somasundaran, K. V. \& Goyal, R. C. (2002). Current Health Scenario in Rural India. Aust. J. Rural Health, 10, 129-135.

Planning Commission of India. (2011). High Level Expert Group Report on Universal Health Coverage for India.

Pradhan, B. K., Roy, P. K., Saluja, M. R. \& Venkatram, S. (2000). Rural-Urban Disparities: Income Distribution, Expenditure Pattern and Social Sector. Economic and Political Weekly, 35(28/29), 2527-2529+25312539.

Rao, V. M. (1983). Barriers in Rural Development. Economic and Political Weekly, 18(27), 1177-1179, 11821185,1187-1190.

Rosenzweig, M. R. \& Robert, E. (1977). Fertility, schooling, and the economic contribution of children in rural India: An econometric analysis. Econometrica, 4(1),065-1,079.

Schutjer, W. A., Stokes, C. S. \& Poindexter, J. R. (1983). Farm Size, Land Ownership, and Fertility in Rural Egypt. Land Economics, 59(4), 393-403.

Wamani, H., Tylleskar, T., Astrom, A. N., Tumwine, J. K. \& Peterson, S. (2004). Mothers' education but not fathers' education, household assets or land ownership is the best predictor of child health inequalities in rural Uganda. International Journal for Equity in Health, doi: 10.1186/1475-9276-3-9. 